\title{
8. SEISMIC PROPERTIES AND REFLECTIVITY OF NORTH PACIFIC OCEAN CHERTS ${ }^{1}$
}

\author{
R.H. Wilkens, ${ }^{2}$ N.I. Christensen,${ }^{3}$ and J.A. Collins ${ }^{4}$
}

\begin{abstract}
Identification of a sediment/basement contact using seismic reflection recordings has proven to be extremely difficult in wide areas of the North Pacific Ocean owing to the presence of massive, highly reflective chert layers within the sediment column. Leg 136 of the Ocean Drilling Program recovered coherent pieces of chert of sufficient size for the first comprehensive laboratory measurements of the seismic properties of this material. Compressional-wave velocities of six samples at 40-MPa confining pressure averaged $5.33 \mathrm{~km} / \mathrm{s}$, whereas shear-wave velocities at the same pressure averaged $3.48 \mathrm{~km} / \mathrm{s}$. Velocities were independent of porosity, which ranged from $5 \%$ to $13 \%$, suggesting that pores within the samples were mostly high aspect ratio vugs as opposed to low aspect ratio cracks. Back-scattered electron images made with a scanning electron microscope confirmed this observation. Acoustic impedances were calculated for the chert samples and from shipboard measurements of the red clay sediment overlying the chert layers. An extremely large compressional-wave reflection coefficient $(0.73)$ characterized the interface between the two lithologies. A synthetic seismogram was calculated using chert and typical pelagic carbonate properties to illustrate the influence of chert layers on a marine seismic-reflection section. Compressional-wave to shear-wave velocity ratios of the chert samples $\left(V_{p} / V_{s}=1.53\right)$ are close to that of single-crystal quartz in spite of variable porosity. Shear-wave reflection coefficients are estimated to be approximately 0.94 . A compressional-wave reflection coefficient for a basement/sediment (carbonate) interface is estimated to be approximately 0.50 , significantly less than that of sediment $/$ chert.
\end{abstract}

\section{INTRODUCTION}

Leg 136 of the Ocean Drilling Program (ODP) investigated two sites (Site 842 and Site 843) approximately $225 \mathrm{~km}$ south-southwest of the island of Oahu in the Hawaiian Island chain (Fig. 1). The major objective of Leg 136 was to establish a test site for the Ocean Seismic Network (OSN) — a reentry hole drilled into the oceanic basement for placement of a downhole seismometer (Dziewonski, Wilkens, Firth, et al., 1992). Previous attempts to reach basement during the Deep Sea Drilling Project had been frustrated by layers of chert in the sedimentary column that proved impenetrable with the technology available (Winterer, Riedel, et al., 1971). Leg 136 was able to reach basement at Site 843 , although severe drilling problems (high torque on the drill string, poor recovery) were encountered owing to the cherts, and recovery was limited for most of the sedimentary section to cherts in wash cores.

Chert layers within the sediments posed another problem familiar in the North Pacific Ocean. Reflection seismic records did not reveal two-way traveltime to the sediment/volcanic basement interface because of the extremely reflective nature of the chert-sediment layers (Collins et al., 1992). Reflections were seen as deep as $0.5 \mathrm{~s}$ below the sediment surface, although expanding-spread profile data collected earlier in the area suggested a basement depth of $0.26 \mathrm{~s}$ (Brocher and ten Brink, 1987; Lindwall, 1991). Data from site surveys illustrate the reverberant nature of the reflection records (Fig. 2).

Cherts layers have long been known as sources of strong reflectors in oceanic sediments (e.g., the porcellanite Horizon $\mathrm{A}^{\mathrm{c}}$ in the western Atlantic; Tucholke, 1981; Wilkens et al., 1987). However, the recovery of samples of these cherts sufficiently large for laboratory study has been rare. Wash Cores 136-842C-1W and 136-843A-2W drilled during Leg 136 recovered chert in sufficient quantity to allow the comprehensive laboratory study of seismic properties. To our knowledge, this is the first such study in the literature.

\footnotetext{
'Wilkens, R.H., Firth, J., Bender, J., et al., 1993.Proc. ODP, Sci. Results, 136: College Station, TX (Ocean Drilling Program).

${ }^{2}$ Hawaii Institute of Geophysics, University of Hawaii, Honolulu, HI 96822, U.S.A

${ }^{3}$ Department of Geosciences, Purdue University, West Lafayette, IN 47907, U.S.A.

${ }^{4}$ Woods Hole Oceanographic Institution, Woods Hole, MA 02543, U.S.A.
}

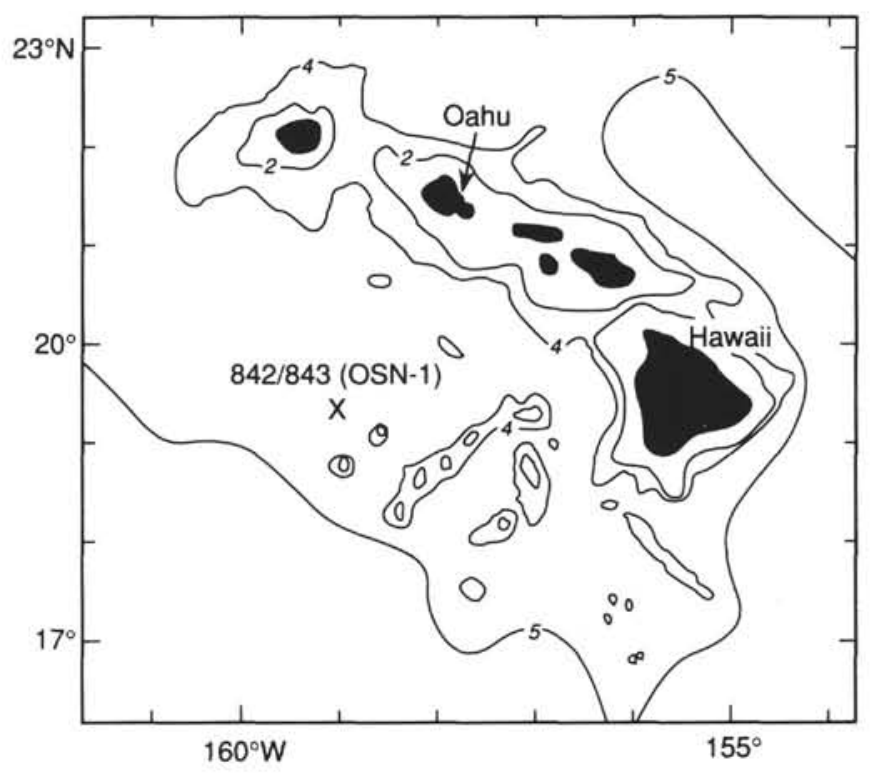

Figure 1. Location of ODP Sites 842 and 843 , Ocean Seismographic Network station number 1 (OSN 1) approximately $225 \mathrm{~km}$ south-southwest of the Hawaiian island of Oahu.

\section{LABORATORY STUDIES}

\section{Samples}

The lithologic columns are similar at Sites 842 and 843. Approximately $35 \mathrm{~m}$ of clay and claystone overlie $200 \mathrm{~m}$ of chert interlayered with probable poorly consolidated Cretaceous pelagic carbonate (Dziewonski, Wilkens, Firth, et al., 1992). Carbonate sediments recovered from the washed (chert layer) intervals consist of small pods attached to 1 - to 10 -cm-long chert core sections. A complete stratigraphy and the exact position of the chert layers were impossible to determine because of the poor recovery. Well logs were not able to add significant information owing to poor hole conditions. X-ray-diffraction measurements performed aboard ship identified the chert samples as composed 


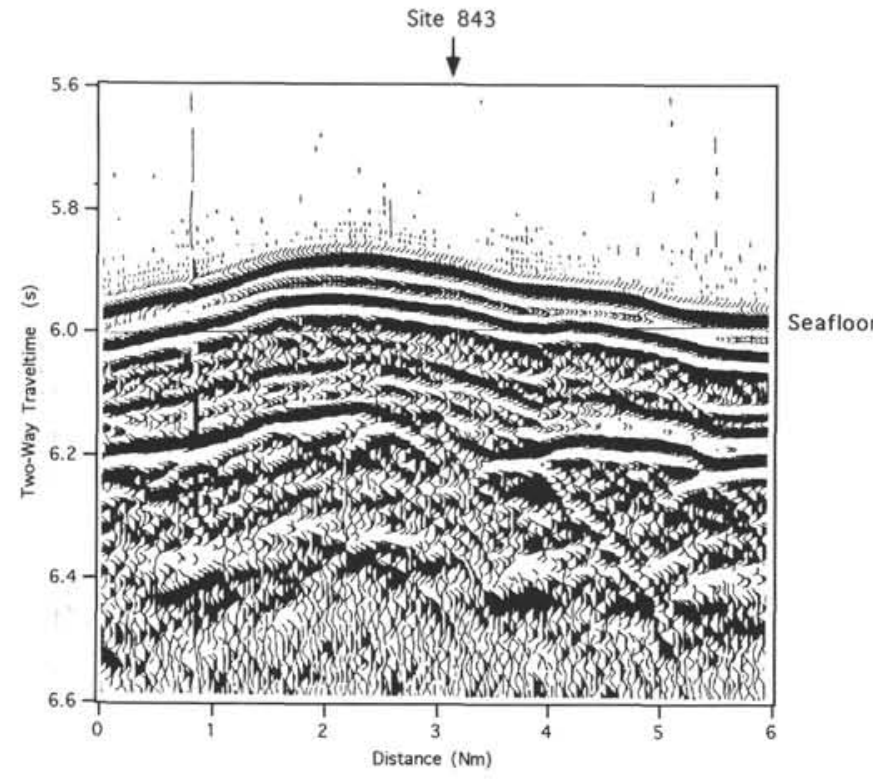

Figure 2. Seismic-reflection data collected during the site survey. Note the reverberant nature of the record. Basement should be seen at approximately $0.26 \mathrm{~s}$ two-way traveltime below the seafloor.

of cryptocrystalline quartz. Quartz is the end product of the oceanic silica diagenesis series that starts with biogenic opal-A, converting to opal-CT, and eventually totally recrystallizing as quartz (Wise and Weaver, 1974; Hein et al., 1983).

Chert samples were examined using a back-scattered electron detector in a scanning electron microscope (Pye and Krinsley, 1984). Typical examples of chert microstructure are illustrated by the digital images in Figure 3. Samples were cut and polished to a flat surface to expose cross sections. The intensity of the back-scattered electrons is dependent on the density of the minerals scanned by the electron beam. Bright areas are of high density and gray areas of relatively lower density material. Holes (pores) appear black, and some are surrounded by bright rims caused by electron charging of the sample surface at sharp corners. The small variation in intensity over most of the images illustrates the predominantly monomineralic nature of the samples. Small zones of higher back-scatter are from small inclusions of carbonate within the chert matrix.

All of the samples showed layering in hand sample. The nature of the porosity contrast across a layer boundary is illustrated in Figure $3 \mathrm{~A}$. Image processing revealed that the lower half of the image contained approximately $1 \%$ porosity, whereas the upper half had $13 \%$ porosity. Porosities of the samples were calculated from bulk-density measurements of minicores used for velocity measurements. Assuming a quartz grain density of $2.65 \mathrm{~g} / \mathrm{cm}^{3}$, porosities ranged from $5.5 \%$ to $13 \%$. Pores are examined in higher magnification in Figure 3B. Note that the pore cross sections can be approximated by relatively large aspect ratios typical of vuggy porosity. (The aspect ratio here is defined as the ratio of the minor to major axes of an ellipse fit to the pore area. Spherical pores have an aspect ratio of 1.0, whereas cracks have aspect ratios much less than 1.0.) Cracks are absent. Theoretical studies show that velocity-porosity relationships are greatly influenced by crack abundance, and much less by high aspect ratio pores (e.g., Kuster and Toksöz, 1974; see discussion of velocity-porosity relationship in the following).

\section{Velocity Measurements}

Six samples of chert representative of recovered material were selected for velocity measurements. Cylindrical cores were weighed and measured to calculate bulk densities and jacketed with copper foil to exclude the pressure medium for velocity measurements as a function of pressure (Table 1).

The traveltimes of compressional and shear waves were measured using a pulse transmission technique (Birch, 1960; Christensen, 1985), and velocities were calculated from these traveltimes and sample lengths. Natural resonant frequencies of the compressional- and shearwave transducers were $1 \mathrm{MHz}$. Measurements were made at elevated hydrostatic confining pressures using a single-stage intensifier pres-
A

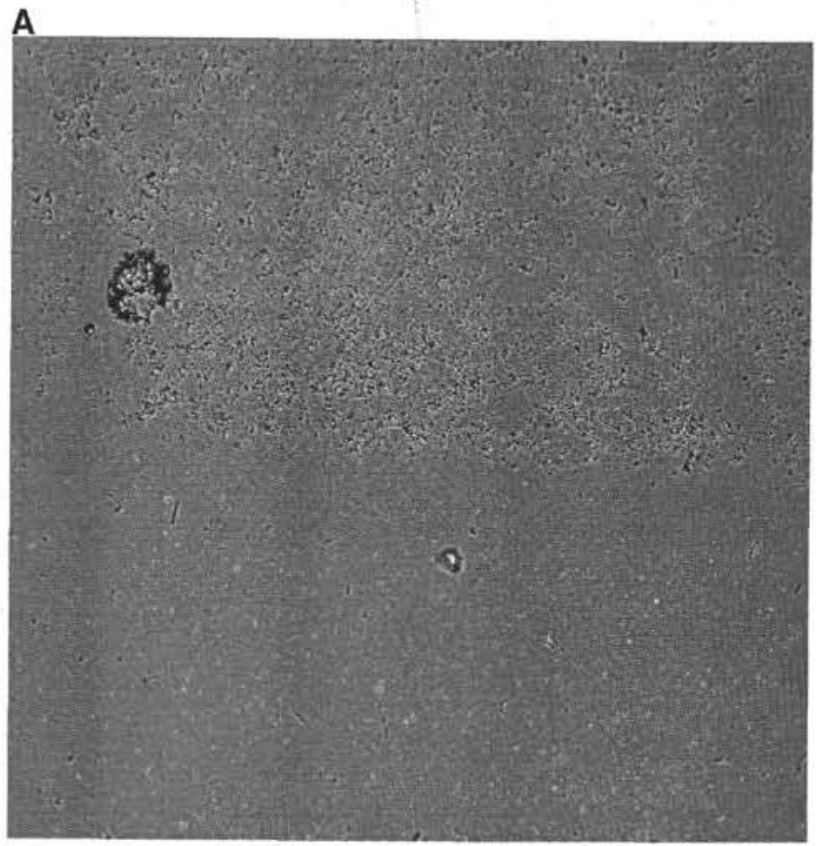

B

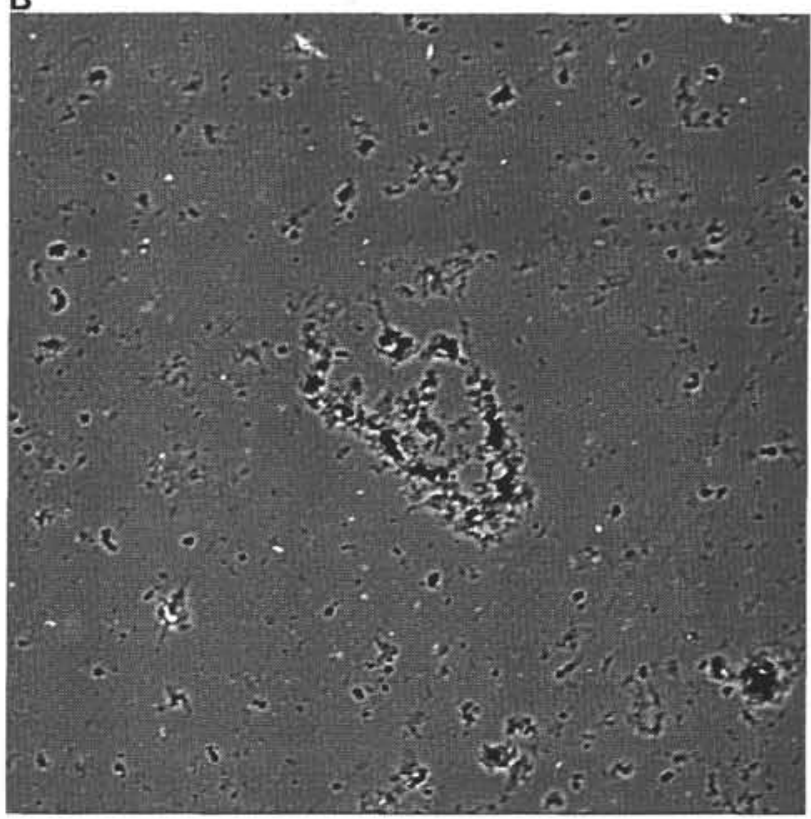

Figure 3. Digital images of back-scattered electron micrographs. Gray areas are quartz, lighter areas are small carbonate inclusions, and darkest areas are pores. A. Layer boundary separating low- and high-porosity chert (Sample 136-843A-2W, 10-13 cm; 50x). B. Close-up of pores in chert (Sample 136-843A-2W, 42-45 $\mathrm{cm} ; 250 \times)$. 
Table 1. Laboratory results of measurements at elevated confining pressure.

\begin{tabular}{|c|c|c|c|c|c|c|c|}
\hline $\begin{array}{c}\text { Pressure } \\
\text { (MPa) }\end{array}$ & $\begin{array}{c}842 \mathrm{C}-1 \mathrm{~W}-1, \\
34-37 \mathrm{~cm}\end{array}$ & $\begin{array}{c}842 \mathrm{C}-1 \mathrm{~W}-1 \\
43-45 \mathrm{~cm}\end{array}$ & $\begin{array}{c}843 \mathrm{~A}-2 \mathrm{~W}-1 \\
10-13 \mathrm{~cm}\end{array}$ & $\begin{array}{c}843 \mathrm{~A}-2 \mathrm{~W}-1 \\
22-26 \mathrm{~cm}\end{array}$ & $\begin{array}{c}843 \mathrm{~A}-2 \mathrm{~W}-1 \\
35-37 \mathrm{~cm}\end{array}$ & $\begin{array}{c}843 \mathrm{~A}-2 \mathrm{~W}-1 \\
42-45 \mathrm{~cm}\end{array}$ & Average \\
\hline \multicolumn{8}{|c|}{ Compressional-wave velocity $(\mathrm{km} / \mathrm{s})$} \\
\hline 10 & 5.216 & 5.394 & 5.177 & 5.289 & 5.225 & 5.289 & 5.265 \\
\hline 20 & 5.265 & 5.432 & 5.220 & 5.312 & 5.247 & 5.339 & 5.303 \\
\hline 30 & 5.289 & 5.451 & 5.241 & 5.322 & 5.261 & 5.365 & 5.322 \\
\hline 40 & 5.305 & 5.464 & 5.252 & 5.329 & 5.273 & 5.383 & 5.334 \\
\hline 50 & 5.316 & 5.473 & 5.260 & 5.335 & 5.282 & 5.396 & 5.344 \\
\hline 60 & 5.324 & 5.480 & 5.266 & 5.341 & 5.291 & 5.405 & 5.351 \\
\hline 70 & 5.330 & 5.486 & 5.271 & 5.347 & 5.298 & 5.413 & 5.358 \\
\hline 80 & 5.335 & 5.492 & 5.276 & 5.354 & 5.305 & 5.420 & 5.364 \\
\hline 90 & 5.340 & 5.497 & 5.280 & 5.360 & 5.312 & 5.426 & 5.369 \\
\hline 100 & 5.344 & 5.502 & 5.284 & 5.365 & 5.318 & 5.431 & 5.374 \\
\hline \multicolumn{8}{|c|}{ Shear-wave velocity $(\mathrm{km} / \mathrm{s})$} \\
\hline 10 & 3.452 & 3.527 & 3.393 & 3.479 & 3.377 & 3.478 & 3.451 \\
\hline 20 & 3.463 & 3.536 & 3.407 & 3.492 & 3.392 & 3.504 & 3.466 \\
\hline 30 & 3.469 & 3.541 & 3.418 & 3.499 & 3.400 & 3.519 & 3.474 \\
\hline 40 & 3.473 & 3.544 & 3.426 & 3.503 & 3.405 & 3.530 & 3.480 \\
\hline 50 & 3.476 & 3.545 & 3.433 & 3.507 & 3.409 & 3.538 & 3.485 \\
\hline 60 & 3.478 & 3.547 & 3.439 & 3.509 & 3.411 & 3.544 & 3.488 \\
\hline 70 & 3.480 & 3.548 & 3.443 & 3.512 & 3.414 & 3.550 & 3.491 \\
\hline 80 & 3.482 & 3.549 & 3.447 & 3.514 & 3.416 & 3.555 & 3.494 \\
\hline 90 & 3.483 & 3.551 & 3.451 & 3.516 & 3.417 & 3.559 & 3.496 \\
\hline 100 & 3.485 & 3.552 & 3.454 & 3.517 & 3.419 & 3.563 & 3.498 \\
\hline \multicolumn{8}{|c|}{ Bulk density $\left(\mathrm{g} / \mathrm{cm}^{3}\right)$} \\
\hline & 2.477 & 2.560 & 2.469 & 2.536 & 2.557 & 2.438 & 2.506 \\
\hline
\end{tabular}

sure generating system connected to a pressure vessel with an internal working space $15 \mathrm{~cm}$ long and $4.5 \mathrm{~cm}$ in diameter. The pressure medium was hydraulic oil. Velocity measurements of individual samples are estimated to be accurate to better than 1\% (Birch, 1960).

Compressional-wave velocities measured at $40-\mathrm{MPa}$ confining pressure (approximately the hydrostatic pressure at Sites 842 and 843) are plotted vs. calculated porosity in Figure 4 . A plot of average compressional-wave velocity vs. confining pressure is shown in Figure 5. Data displayed in Figure 4 imply a poor dependence of velocity on porosity, as is typical of rocks with vuggy porosity (Wyllie et al., 1958). Furthermore, the small dependence of velocity on pressure (Fig. 5) evidences the lack of crack porosity in the samples, because crack closure as pressure increases would be expected to result in a large velocity increase. The chert samples examined in this study do not contain the types of microcracks typical of rocks such as seafloor basalts (e.g., Wilkens et al., 1991). In the following discussion it is assumed that the laboratory samples are characteristic of entire chert layers in the sediment column.

\section{CHERT REFLECTIVITY}

Seismic-reflection amplitudes at normal incidence are characterized by differences in the acoustic impedance of materials across an interface. Acoustic impedance $(Z)$ is defined by the product of velocity and density:

$$
Z=V \times \rho,
$$

where $V$ is compressional-wave velocity and $\rho$ is bulk density. The reflection coefficient $(R C)$ for normal incidence is calculated as:

$$
R C=\frac{\left(Z_{2}-Z_{1}\right)}{\left(Z_{2}+Z_{1}\right)}
$$

(Sherif, 1975) where $Z_{1}$ is the acoustic impedance of the upper layer and $Z_{2}$ the acoustic impedance of the lower layer. The sign of $R C$ dictates whether the reflected wave is in phase (positive) or $180^{\circ}$ out of phase (negative) with the incident wave.

To illustrate the contrast in $Z$ between chert and normal sediments, we have plotted the compressional-wave velocity of the chert samples vs. density as well as a typical clay recovered in a Leg 136 upper core

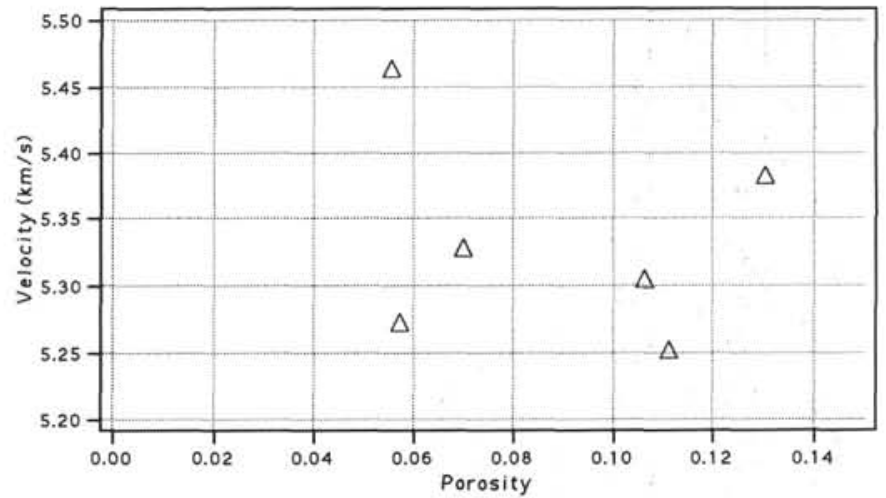

Figure 4. Compressional-wave velocity measured at $40-\mathrm{MPa}$ confining pressure vs. calculated porosity of cherts in this study. The data do not exhibit a velocity-porosity dependence.

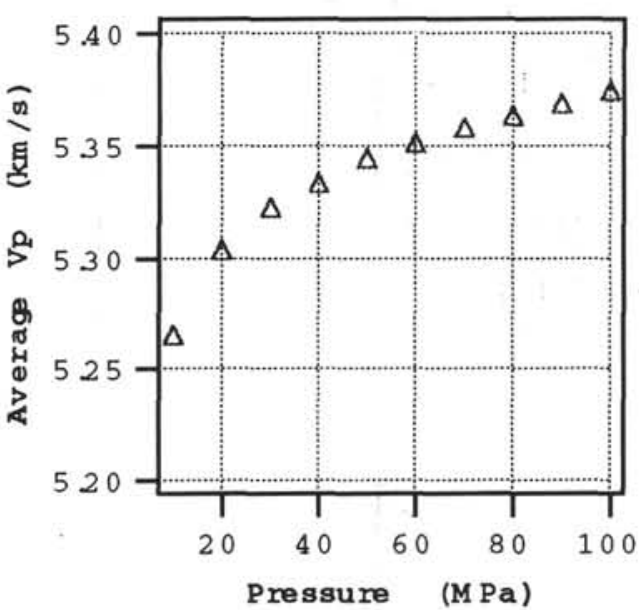

Figure 5. Average compressional-wave velocity vs. confining pressure for cherts. The relatively small increase in velocity with pressure indicates few cracks in the laboratory samples. 
section (Fig. 6). Lines of constant $Z$ have been superimposed on the figure. Chert samples have $Z$ values between 13 and 14 , whereas the North Pacific red clay, based on shipboard measurements (Dziewonski, Wilkens, Firth, et al., 1993), is at about 2. Calculation of $R C$ for the two lithologies results in an average value of 0.73 . Sherif (1975) stated that a good to fair reflector is generated by a $R C=0.05$.

To demonstrate the profound effect that the presence of chert has on the seismic response of sedimented oceanic crust, we have calculated normal-incidence reflectivity synthetic seismograms for the interbedded carbonate/chert velocity model shown in Figure 7. The model values are listed in Table 2 . The synthetic seismogram shown in Figure 8 was calculated with a reflectivity algorithm (Kennett and Kerry, 1979); it includes the effects of interbed multiples and of frequency-dependant attenuation. The source function used in all the synthetic seismogram calculations shown in this paper is the measured response of a six element subset of the air-gun array presently used by the Ewing. This sub-array, consisting of air-gun chamber volumes of $500,305,200,145,120$, and 80 in. $^{3}$ has been used successfully for high-resolution reflection studies (J. Diebold, pers. comm., 1993). The seismogram shown in Figure 8 represents the response of the velocity model to a vertically propagating plane wave and, consequently, does not include the effects of geometrical spreading. The predicted locations of reflections from the layer boundaries of the velocity model are marked by asterisks in Figure 8. Reflections from the deeper chert layers and from the sediment/basement interface are of small magnitude.

The synthetic seismogram shown in Figure 8 is easier to understand by examining the complete seismic response of a portion of the velocity model and the partial responses of the complete velocity model. Figure 9A shows the synthetic seismogram calculated for a model similar to that shown in Figure 7 but which does not include the chert layers. The seismogram shows two reflection events from the seafloor and the sediment/basement interface. (The reflections from the carbonate-carbonate interfaces are negligible.) The great difference in the magnitude of the basement reflection from that seen in the calculation for the complete model must arise from the presence of the chert layers. This calculation has the additional value of clearly showing the source function. The manner in which the chert layers affect the seismic response can be further understood by calculating the partial response of the model shown in Figure 7. Figure 9B shows the synthetic seismogram calculated without including the effects of interbed multiples. At the scale of the plot, which is identical to that of Figure 8, the basement reflection is not visible. This demonstrates (1) that the reflection event coincident with the lowermost asterisk in Figure 8 is an interbed multiple, and (2) the interbed multiples do not obscure an otherwise recognizable basement reflection. Rather, the low-amplitude basement reflection seen in Figure 8 is due to the very large reflection coefficient of the chert beds that results in a relatively small amount of seismic energy being transmitted through the chert layers to and from the sediment/basement interface. The magnitude of the interbed multiples is greatly affected by the attenuation in the carbonate layers. Figure 9C shows a synthetic seismogram calculated for the model listed in Table 2, except the Q (seismic quality factor) of the carbonate layers is 200 . This value is unrealistically large. The large amplitude events that are not marked by asterisks are interbed multiples.

\section{DISCUSSION}

Laboratory measurements and synthetic seismograms have been used to illustrate the extreme reflectivity of chert layers when they are present in typical oceanic sediment columns. The data allow several other interesting observations. Although it was known that many oceanic cherts are composed of cryptocrystalline quartz, it was not understood how porosity, either in the form of cracks or vugs, may affect seismic properties. It is interesting that $V_{p} / V_{s}$ ratios for the cherts in this study are all near 1.50. They are much closer to the values of single-crystal quartz $\left(V_{p} / V_{s}=1.48\right.$, McSkimin et al., 1965) than to

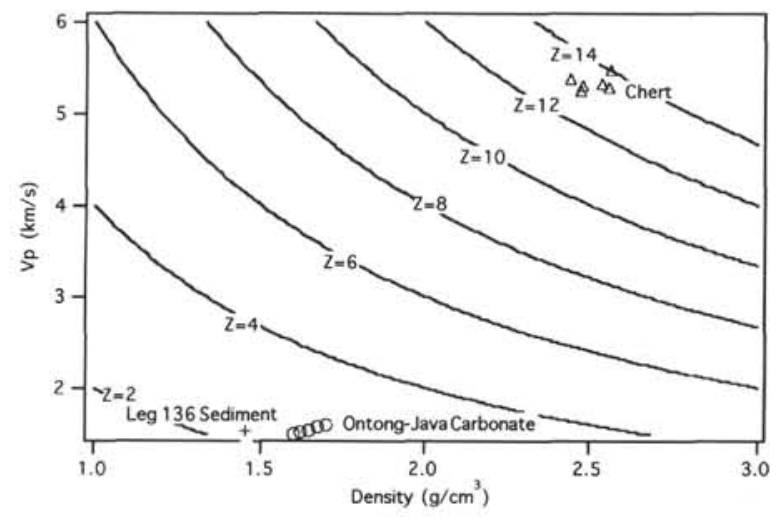

Figure 6. Compressional-wave velocity vs. density for cherts, carbonate ooze and chalk, and red clay. Contours of acoustic impedance $(Z)$ have been superimposed on the plot. A large difference in $Z$ values means a large reflection coefficient at a boundary between two materials.

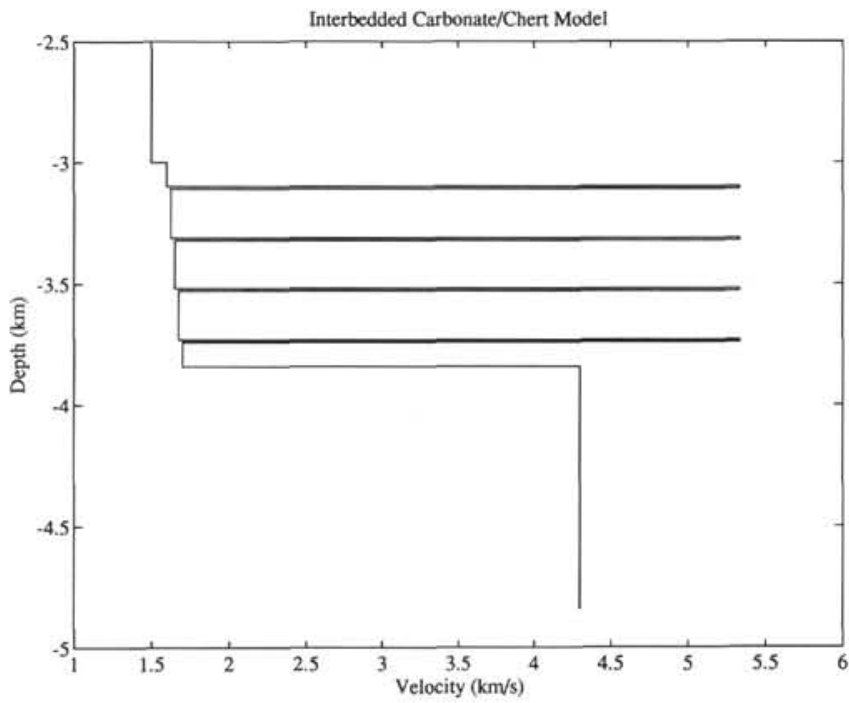

Figure 7. Compressional-wave velocity-depth model for an interbedded carbonate $\left(V_{p}=1.6-1.7 \mathrm{~km} / \mathrm{s}\right)$ and chert $\left(V_{p}=5.334 \mathrm{~km} / \mathrm{s}\right)$ overlying igneous crust $\left(V_{p}=4.3 \mathrm{~km} / \mathrm{s}\right)$. This model, the complete parameters of which are listed in Table 2, was used to calculate the normal-incidence, synthetic seismograms shown in this paper.

Table 2. Values used to calculate the synthetic seismograms shown in this study.

\begin{tabular}{ccrr}
\hline $\begin{array}{c}\text { Velocity } \\
(\mathrm{km} / \mathrm{s})\end{array}$ & $\begin{array}{c}\text { Thickness } \\
(\mathrm{km})\end{array}$ & $\begin{array}{r}\text { Density } \\
\left.\left(\mathrm{g}^{\mathrm{cm}}\right)^{3}\right)\end{array}$ & \multicolumn{1}{c}{$\mathrm{Q}$} \\
\hline & & & \\
1.600 & 0.100 & 1.500 & 10,000 \\
5.334 & 0.010 & 2.506 & 1000 \\
1.625 & 0.200 & 1.523 & 50 \\
5.334 & 0.010 & 2.506 & 1000 \\
1.650 & 0.200 & 1.547 & 50 \\
5.334 & 0.010 & 2.506 & 1000 \\
1.675 & 0.200 & 1.570 & 50 \\
5.334 & 0.010 & 2.506 & 1000 \\
1.700 & 0.100 & 1.594 & 50 \\
4.300 & & 2.800 & 200 \\
\hline & & &
\end{tabular}

other oceanic rocks (average about 1.80 ) or unconsolidated and partially consolidated sediment $\left(V_{p} / V_{s}>2.00\right)$.

Reflection coefficients of 0.73 can also be compared to what may be expected at the basement interface in a pelagic carbonate sediment column. It is little surprise that chert layers mask basement reflections in the North Pacific Ocean. Assuming chalk with a compressional- 


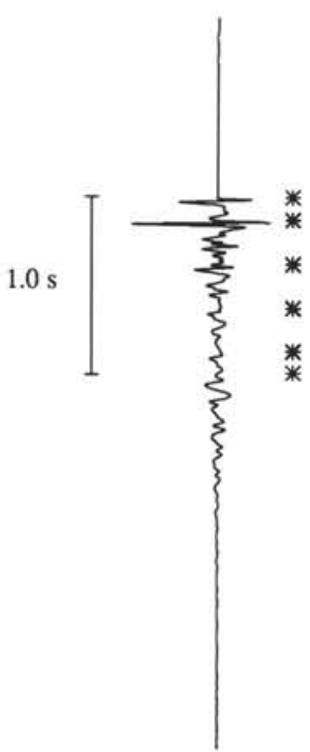

Figure 8 . Normal-incidence synthetic seismogram calculated for the velocity model of Table 2. The seismogram includes the effects of interbed multiples and frequency-dependant attenuation. The source function is that for a six-element, air-gun array with chamber volumes of $500,305,200,145,120$, and 80 $\mathrm{in}^{3}$. (The source function can be seen in Figure 9.) The predicted locations of the reflections from the layer boundaries shown in Figure 7 are indicated by the asterisks. Note the low amplitude of the basement reflection event marked by the lowermost asterisk.
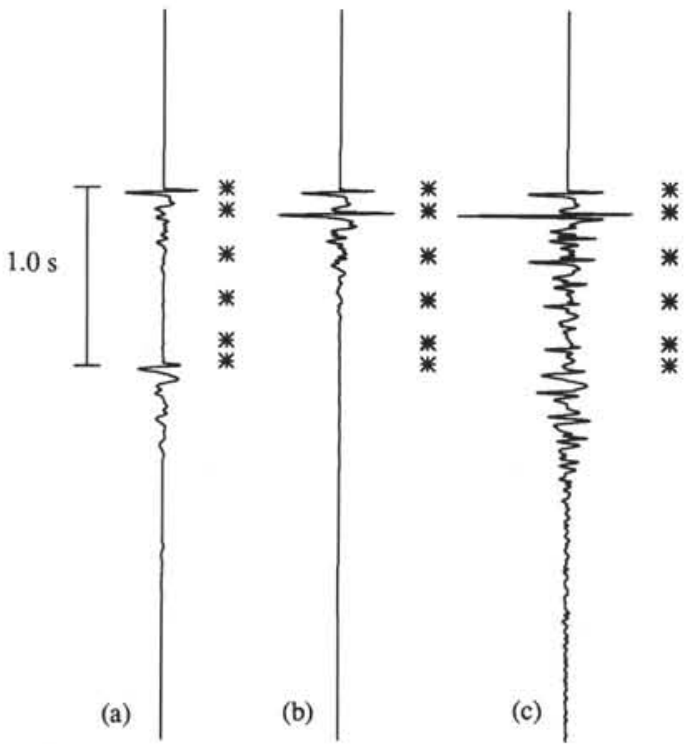

Figure 9. A. Normal-incidence synthetic seismogram calculated for an earth model identical to that listed in Table 2 but which does not include the chert layers. The seismogram includes the effects of interbed multiples and frequency-dependant attenuation. The two large reflection events are from the seafloor and from the top of basement. The earlier event shows clearly the source function used to generate all of the synthetic seismograms shown in this paper. B. Normal-incidence synthetic seismogram calculated for an earth model identical to that listed in Table 2. The synthetic seismogram does not include the effects of interbed multiples. The basement reflection is not visible at the scale of this plot. C. Normal-incidence synthetic seismogram calculated for an earth model identical to that listed in Table 2 except the $Q$ of the carbonate layers is 200 . The seismogram includes the effects of interbed multiples and frequency-dependant attenuation. wave velocity of $1.80 \mathrm{~km} / \mathrm{s}$ and bulk density of $1.7 \mathrm{~g} / \mathrm{cm}^{3}$, and a basalt velocity of $3.50 \mathrm{~km} / \mathrm{s}$ with a density of $2.40 \mathrm{~g} / \mathrm{cm}^{3}$, the resultant $R C$ is 0.47 , considerably less than a chert/sediment boundary.

As large as the reflection coefficients are for compressional-wave velocities at the chert/sediment interfaces, it is probable that shearwave reflectivity is even greater. Following the arguments of Hamilton (1976), shear-wave velocities in the clays of Leg 136 sediments can be estimated to be no greater than approximately $0.200 \mathrm{~km} / \mathrm{s}$. Shear-wave velocity this slow in the clays results in a reflection coefficient of 0.94 with cherts. At non-normal incidence this boundary would produce a lot of shear-wave conversion.

Cherts are volumetrically abundant in North Pacific Ocean sediment columns, but they occur in many settings throughout the world oceans. Because they contrast so greatly with more normal pelagic sediment in their seismic properties, they are significant contributors to seismic-reflection records even when their occurrence is relatively insignificant in terms of overall sediment lithology.

\section{ACKNOWLEDGMENTS}

Velocity measurements were made at Purdue University by Jianping Xu. Chert samples were prepared for back-scatter imaging by Rolf Arvidson at the University of Hawaii. Rick Carlson and Juan Lorenzo provided careful and helpful reviews. This work was supported by a post-cruise grant from the National Science Foundation through JOI Inc. to R.W. and by grants from the Office of Naval Research to N.C. and R.W.

\section{REFERENCES ${ }^{*}$}

Birch, F., 1960. The velocity of compressional waves in rocks to 10 kilobars, 1. J Geophys. Res., 65:1083-1102.

Brocher, T.M., and ten Brink, U.S., 1987. Variations in oceanic Layer 2 elastic velocities near Hawaii and their correlation to lithospheric flexure. $J$. Geophys. Res., 92:2647-2661.

Christensen, N.I., 1985. Measurements of dynamic properties of rocks at elevated temperatures and pressures. In Pincus, H.J., and Hoskins, E.R. (Ed.), Measurements of Rock Properties at Elevated Pressures and Temperatures: Philadelphia (Am. Soc. for Testing and Materials), ASTM STP 869:93-107.

Collins, J.A., Duennebier, F., and Shipboard Scientific Party, 1992. Site survey and underway geophysics. In Dziewonski, A., Wilkens, R., Firth, J., et al., Proc. ODP, Init. Repts., 136: College Station, TX (Ocean Drilling Program), 27-34.

Dziewonski, A., Wilkens, R., Firth, J., et al., 1992. Proc. ODP, Init. Repts., 136: College Station, TX (Ocean Drilling Program).

Hamilton, E.L., 1976. Shear wave velocity versus depth in marine sediments: a review. Geophysics, 41:985-996.

Hein, J.R., Sancetta, C., and Morgenson, L.A., 1983. Petrology and geochemistry of silicified upper Miocene chalk, Costa Rica rift, Deep Sea Drilling Project Leg 69. In Cann, J.R., Langseth, M.G., Honnorez, J., Von Herzen, R.P., White, S.M., et al., Init. Repts. DSDP, 69: Washington (U.S. Govt. Printing Office), 395-422.

Kennett, B.L.N., and Kerry, N.J., 1979. Seismic waves in a stratified half space. Geophys. J. R. Astron. Soc., 57:557-583.

Kuster, G.T., and Toksöz, M.N., 1974. Velocity and attenuation of seismic waves in two-phase media: Part I - theoretical formulations. Geophysics, 39:587-607.

Lindwall, D.A., 1991. Old Pacific crust near Hawaii: a seismic view. J. Geophys. Res., 96:8191-8203.

McSkimin, H.J., Andreatch, P., Jr., and Thurston, R.N., 1965. Elastic moduli of quartz versus hydrostatic pressure at $25^{\circ}$ and $-195.8^{\circ} \mathrm{C}$. J. Appl. Phys., $36: 1624-1632$

Pye, K., and Krinsley, D.H., 1984. Petrographic examination of sedimentary rocks in the SEM using backscattered electron detectors. J. Sediment. Petrol., 54:877-888.

\footnotetext{
Abbreviations for names of organizations and publications in ODP reference lists follow the style given in Chemical Abstracts Service Source Index (published by American Chemical Society).
} 
Sheriff, R.E., 1975. Factors affecting seismic amplitudes. Geophys. Prospect., $23: 125-128$.

Tucholke, B.E., 1981. Geologic significance of seismic reflectors in the deep western North Atlantic basin. Spec. Publ.-Soc. Econ. Paleontol. Mineral., 32:23-37.

Wilkens, R.H., Fryer, G.J., and Karsten, J., 1991. Evolution of porosity and seismic structure of upper oceanic crust: importance of aspect ratios. $J$. Geophys. Res., 96:17891-17995.

Wilkens, R.H., Schreiber, B.C., Caruso, L., and Simmons, G., 1987. The effects of diagenesis on the microstructure of Eocene sediments bordering the Baltimore Canyon Trough. In Poag, C.W., Watts, A.B., et al., Init. Repts. DSDP, 95: Washington (U.S. Govt. Printing Office), 527-547.

Winterer, E.L., Riedel, W.R., et al., 1971. Init. Repts. DSDP, 7 (Pt. 1): Washington (U.S. Govt. Printing Office).
Wise, S.W., Jr., and Weaver, F.M., 1974. Chertification of oceanic sediments, In Hsü, K.J., and Jenkyns, H.C. (Eds.), Pelagic Sediments: on Land and under the Sea. Spec. Publ. Int. Assoc. Sedimentol., 1:301-326.

Wyllie, M.R.J., Gregory, A.R., and Gardner, G.H.F., 1958. An experimental investigation of factors affecting elastic wave velocities in porous media. Geophysics, 23:400.

Date of initial receipt: 13 January 1993

Date of acceptance: 28 June 1993

Ms 136SR-210 